\section{Biologie moléculaire: L'ARN}

\section{messager} de transfert,

un nouveau

\section{venu qui sépare les élus des damnés}

\author{
On connaissait les ARN \\ messagers, les ARN de \\ transfert et les ARN \\ ribosomiques, tous impliqués \\ dans la traduction des ARN \\ messagers en protéines. Voici \\ maintenant qu'apparaît une \\ espèce hybride étrange, un \\ "ARN messager de transfert" \\ auquel est dévolue la tâche, \\ au moins chez les bactéries, \\ de vouer à la destruction \\ protéolytique les protéines \\ anormales dans leur partie \\ carboxyterminale car \\ synthétisées à partir d'un \\ ARNm dépourvu de codon \\ stop. Cet ARNmt commence \\ par se comporter comme un \\ ARNt alanine... puis est lu \\ sur dix codons comme un \\ messager dont la séquence \\ codante est interrompue par \\ un codon stop canonique. Les \\ protéines terminées par cette \\ extension de 11 acides aminés \\ seront sélectivement et \\ rapidement dégradées par \\ des protéases spécifiques.
}

\title{
Variégation de l'effet de position d'un transgène dépendante du LCR
}

Le terme LCR (locus control region) désigne une séquence régulatrice qui, chez la souris transgénique, contrôle l'expression d'un gène avec une spécificité tissulaire, quel que soit le site d'intégration et à un haut niveau d'expression. Défini et analysé initialement à propos des gènes globine [1], le concept a été étendu à d'autres motifs, unissant une propriété d'ouverture de la chromatine à une activité enhancer. Le groupe de D. Kioussis (Mill Hill, London, GB), après avoir cloné le gène humain $h C D 2$, avait montré que l'expression de ce gène chez la souris transgénique était spécifique des thymocytes, cellules $\mathrm{T}$ circulantes et mégacaryocytes [2] puis, dans une seconde étape, que des séquences flanquantes en 3' du gène étaient susceptibles de lui conférer une expression dont les caractères indiquaient la présence d'un LCR [3]. Des délétions successives avaient ensuite permis de limiter la région LCR à un segment de 2 kb [4]. Dans un travail récent les mêmes auteurs ont disséqué la fonction de ce LCR et mis en évidence une variégation dans l'effet de position induit par l'hétérochromatine [5]. Trois groupes de sites hypersensibles (HSS 1 à 3) ont été mis en évidence dans le segment de 2 kb situé en 3' du gène, dont seul le HSS1 possède des fonctions classiques de enhancer (figure 1). Des lignées de souris transgéniques ont ensuite été établies avec des constructions dans lesquelles ces sites étaient successivement délétés. La mesure par cytométrie de flux de l'expression de l'antigène lymphocytaire CD2 à la surface des cellules a permis de distinguer deux sortes d'effets de position: une expression diminuée dans toutes les cellules dont le profil d'élution reste unimodal, une variégation d'expression dans une certaine proportion de cellules, traduite par une élution bimodale. Dans tous les cas de constructions intégrant les trois groupes de HSS, la distribution observée est unimodale, témoignant d'une expression indépendante du site d'intégration. En revanche, dans le cas des constructions qui ont éliminé le groupe HSS3 (1,5 ou 1,3 kb), la distribution est mosaïque, unimodale dans huit cas, bimodale dans cinq autres cas, cela indépendamment du nombre de copies intégrées ou de leur orientation. L'observation, identique dans les thymocytes et les cellules $\mathrm{T}$ périphériques, témoigne d'une décision précoce au cours de la différenciation.

Ce phénotype, rappelant les effets de variégation observés chez la drosophile, a pu être confirmé par immunofluorescence in situ (FISH). Par l'examen de coupes au niveau du thymus, les thymocytes s'avèrent groupés en foyers, les uns positifs et les autres négatifs à la coloration immunologique, traduisant une stabilité clonale. La même approche montre, en outre, que le phénomène de variégation est toujours associé à une localisation du transgène dans une région centromérique. On retrouve donc bien chez ces souris les deux caractères d'une variégation par effet de position: variégation d'expression dans un tissu, variégation associée à une localisation centromérique. Aucune variégation n'est observée par ces techniques d'immunofluorescence dans les cas où le transgène inclut le LCR complet.

L'explication de l'inactivation du gène par effet de position est-elle la condensation de la chromatine? Pour tester cette hypothèse, les thy- 


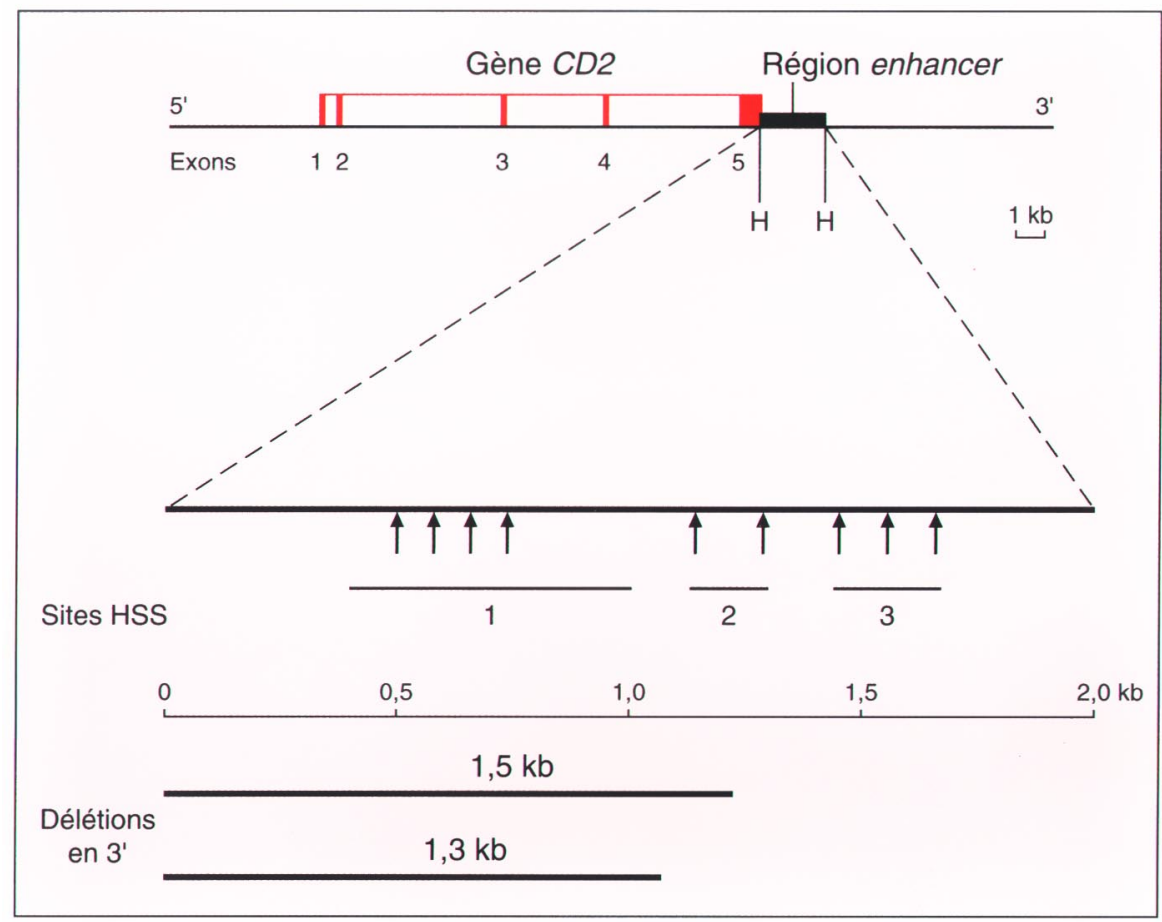

Figure 1. Représentation du gène humain hCD2. II est composé de cinq exons, et en $3^{\prime}$ du gène est située la zone de $2 \mathrm{~kb}$ dans laquelle a été démontrée une fonction enhancer. Cette zone est présentée agrandie, avec trois groupes de sites hypersensibles (HSS1-3). On a représenté enfin les délétions partielles de ces sites introduites dans différentes constructions.

mocytes des souris chez lesquelles avait été retrouvé un effet de variégation ont été séparés selon qu'ils exprimaient ou non le gène $h C D 2$, et leurs noyaux soumis à l'action de la DNase I: des sites de clivage, témoignant d'une chromatine ouverte, ont été observés dans les cellules $h C D 2^{+}$ (exprimant le transgène) mais non dans les cellules $h C D 2$. Dans ces cellules, par conséquent, il est probable qu'en l'absence du site HSS3, le transgène peut être inactivé lorsque, de façon aléatoire, la zone de chromatine dense, «fermée», péricentrique, l'englobe, ce qui est la définition même du processus de variégation. L'expression du transgène par ces cellules positives est aussi fonction du nombre de copies intégrées. Le rôle spécifique du site HSS3 serait de permettre une ouverture locale de la chromatine quelle que soit l'extension de la région hétérochromatique péricentromérique. Ce remarquable travail de dissection d'un LCR serait à rapprocher d'une recherche similaire effectuée par l'équipe de F. Grosveld à propos des gènes de globine $\left(\mathrm{m} / \mathrm{s} n^{\circ} 4\right.$, vol. 12, p. 533).

D.L.

1. Labie D, Krishnamoorthy R. Du nouveau dans les séquences activatrices des gènes de globine (LCR). médecine/sciences 1992; 8: 255-8.

2. Lang G, Wotton D, Owen MJ, Sewell WA, Brown MH, Mason DY, Crumpton MJ, Kioussis D. The structure of the human CD2 gene and its expression in transgenic mice. EMBO J 1988; 7 : 1675-82.

3. Greaves DR, Wilson FD, Lang G, Kioussis D. Human CD2 3'-flanking sequences confer high-level, T-cell-specific, position-independent gene expression in transgenic mice. Cell 1989; 56 : 979-86. 4. Lang G, Mamalaki C, Greenberg D, Yannoutsos $\mathrm{N}$, Kioussis D. Deletion analysis of the human CD2 gene locus control region in transgenic mice. Nucleic Acids Res 1991 ; 19: 5851-6.

5. Festenstein R, Tolaini M, Corbella P, Mamalaki C, Parrington J, Fox M, Miliou A, Jones M, Kioussis D. Locus control region function and heterochromatin-induced position effect variegation. Science 1996; 271 : 1123-5. 